\title{
Metabolite Profiling of Meridianin C In Vivo of Rat by UHPLC/ Q-TOF MS
}

\author{
Guozhe Zhang $\mathbb{D}$, Linxia Xiao, and Liang Qi \\ Department of Translational Medicine, Jiangsu Vocational College of Medicine, 283 South of Republic Road, \\ Yancheng 224005, China \\ Correspondence should be addressed to Liang Qi; qiliangql@126.com
}

Received 31 July 2021; Revised 23 August 2021; Accepted 20 September 2021; Published 21 October 2021

Academic Editor: Sibel A. Ozkan

Copyright $(92021$ Guozhe Zhang et al. This is an open access article distributed under the Creative Commons Attribution License, which permits unrestricted use, distribution, and reproduction in any medium, provided the original work is properly cited.

Meridianin C (MC), as a marine alkaloid, is a potent protein kinase inhibitor which exhibits good anticancer activity. However, the in vivo metabolism of $\mathrm{MC}$ has not been described to date. In this study, an ultra-high performance liquid chromatography/ quadrupole time-of-flight mass spectrometry (UHPLC/Q-TOF MS) method is employed to investigate the in vivo metabolites of MC in rats. Plasma, bile, urine, and feces are collected after a single oral dose of MC. Protein precipitation, solid phase extraction (SPE), and ultrasonic extraction methods are used to prepare samples. Based on the mass spectral fragmentation patterns, elution order, and retrieving literatures, a total of 13 metabolites of MC were detected and tentatively identified, utilizing MetaboLynx software. The metabolic pathways of $\mathrm{MC}$ in rats include $\mathrm{N}$ - or $\mathrm{O}$-glucuronidation, $\mathrm{O}$-sulfation, $\mathrm{N}$-hydroxylation, dihydroxylation, and trihydroxylation. The relative content of the metabolites in each kinds of biological samples is also evaluated. This study will help to understand the in vivo properties of MC for the future usage.

\section{Introduction}

It is universally acknowledged that the discovery and development of drugs is a time-consuming and costly procedure [1]. Absorption, distribution, metabolism, and excretion (ADME) of compound is one of the important considerations in the drug discovery process and can help investigate the drug after administration or injection. And so, ADME characteristics play an important role in drug design. However, drug discoveries and developments are commonly terminated in case of preclinical or clinical prodrug toxicity. Biotransformation of compound in vivo is thought to be one of the factors of drug toxicity [2]. Nowadays, the prodrug screening approach has been performed at a very early stage of drug discovery even drug development. Drugs after oral administration may always be biotransformed by intestinal flora and various metabolizing enzymes to different kinds of phase I and phase II metabolites, which are related to the parent drug. Furthermore, drug metabolic pathways are key factors in optimizing prodrugs for optimal pharmacokinetics properties.
Metabolic pathways of prodrug can help finding latent active metabolites and minimizing potential safety due to biotransformation of reactive or toxic metabolites [3].

The LC/MS technology has been used as an important tool in drug discovery and drug development, owing to its selectivity, sensitivity, and speed. The quadrupole time-offlight mass spectrometry systems can easily provide highresolution mass and accurate mass data, which can efficiently help to calculate the molecular of metabolites. In the past few years, ultrahigh performance liquid chromatography (UHPLC) has become the common approach of ingredients separation for the LC/MS system in the cause of the drug metabolic study, for providing higher throughput, sensitivity, and/or improved selectivity than the traditional HPLC method. So, UHPLC combined with quadrupole time-of-flight mass spectrometry systems has become a commonly technology of the drug metabolism study [4].

Natural products have played close attention in drug discovery because of their easy degradation, environmental friendliness, and unique mechanisms of function [5-9]. Meridianins A-G (Figure 1) are natural products isolated 


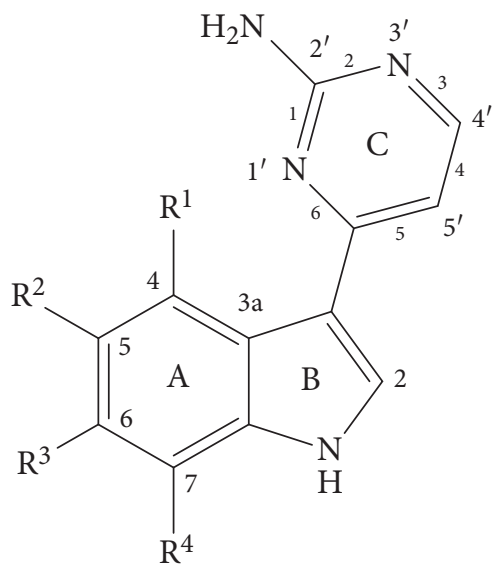

Meridianin A: $\mathrm{R}^{1}=\mathrm{OH}, \mathrm{R}^{2}=\mathrm{R}^{3}=\mathrm{R}^{4}=\mathrm{H}$;

Meridianin B: $\mathrm{R}^{1}=\mathrm{OH}, \mathrm{R}^{2}=\mathrm{R}^{4}=\mathrm{H}, \mathrm{R}^{3}=\mathrm{Br}$;

Meridianin C: $\mathrm{R}^{1}=\mathrm{R}^{3}=\mathrm{R}^{4}=\mathrm{H}, \mathrm{R}^{2}=\mathrm{Br}$;

Meridianin D: $\mathrm{R}^{1}=\mathrm{R}^{2}=\mathrm{R}^{4}=\mathrm{H}, \mathrm{R}^{3}=\mathrm{Br}$;

Meridianin E: $\mathrm{R}^{1}=\mathrm{OH}, \mathrm{R}^{2}=\mathrm{R}^{3}=\mathrm{H}, \mathrm{R}^{4}=\mathrm{Br}$;

Meridianin F: $\mathrm{R}^{1}=\mathrm{R}^{4}=\mathrm{H}, \mathrm{R}^{2}=\mathrm{R}^{3}=\mathrm{Br}$;

Meridianin G: $\mathrm{R}^{1}=\mathrm{R}^{2}=\mathrm{R}^{3}=\mathrm{R}^{4}=\mathrm{H}$;

Figure 1: Structure, nomenclature of meridianins A-G.

from marine organisms. Since the isolation of meridianins A-E in 1998 [10], a total of seven of these alkaloids have been isolated (meridianins A-G) [11]. Meridianin alkaloids exhibit a lot of biological activities, such as anticancer $[5,10]$, protein kinase inhibitory activity [11], antimalarial activity $[12,13]$, antituberculosis activity [13], anti-Alzheimer's disease activity [14], and so on. Especially, meridianin C has been studied showing dramatical anticancer activities $[15,16]$. To our knowledge, meridianins $A-G$ are still not been used as drugs in clinical, and the in vivo metabolisms have not been studied yet. In the present study, UHPLC/QTOF MS is used to characterize and semiquantify the metabolites of MC in rat plasma, bile, urine, and feces for purpose of providing evidence of the course of meridianins in vivo.

\section{Materials and Methods}

2.1. Chemicals and Reagents. MC was prepared in our lab. The structure was determined using ${ }^{1} \mathrm{H}$ NMR (Supplementary Figure S1) and mass spectrometry (MS) methods. The HPLC grade formic acid and acetonitrile were prepared form Thermo Fisher Scientific Co. Ultrapure water (18.2 MQ) was prepared with a Milli-Q water purification system (Millipore, France).

2.2. Animal Experiments [17]. Male Sprague-Dawley rats (220-250 g) were invited from the SPF (Beijing) Biotechnology Co., Ltd. (Beijing, China). They were adapted to new circumstances for one to seven days. The rats were fasted overnight before the drug metabolic study and only allowed free access to water.
Meridianin C powder was dispersed in $0.5 \%$ sodium carboxymethylcellulose (Na-CMC) solution at concentration of $10 \mathrm{mg} / \mathrm{mL}$ and then sonicated until a homogeneous suspension is obtained, which would be used for oral administration. Plasma samples were collected from the suborbital vein to obtain blank plasma. After oral administration of meridianin $\mathrm{C}$ at a dose of $100 \mathrm{mg} / \mathrm{kg}$ bodyweight to two rats, blood was collected from the suborbital vein at the time points of $0.5,1,2,4,8,12$, and $24 \mathrm{~h}$, and all the blood samples were immediately centrifuged at $3,500 \mathrm{rpm}$ for $10 \mathrm{~min}$ at $4^{\circ} \mathrm{C}$ to obtain supernatant plasma and stored at $-80^{\circ} \mathrm{C}$ until analysis. Two rats were used for urine and feces sample collection. Both urine and feces were collected for $0-24 \mathrm{~h}$ after oral administration of MC at the dose of $100 \mathrm{mg} / \mathrm{kg}$ bodyweight. Urine samples were collected every two to four hours and stored at $-20^{\circ} \mathrm{C}$ for later analysis. Feces samples were also stored at $-20^{\circ} \mathrm{C}$ after drying. Two rats were used for bile collection in the period of 0-24 h. After collecting blank bile for a certain amount, rats were orally administrated with the same dosage of MC. The experimental protocol was approved by the Animal Experiment Ethics Review Committee of Jiangsu Vocational College of Medicine (LLSQ-2021-031106).

\subsection{Preparation of Rat Biological Samples [17]}

2.3.1. Plasma. First, $200 \mu \mathrm{L}$ of mixed plasma was diluted with $600 \mu \mathrm{L}$ methanol, vortex-mixed for $2 \mathrm{~min}$, centrifuged at $8,000 \mathrm{rpm}$ for $10 \mathrm{~min}$ to precipitate proteins, and the supernatants were evaporated to dryness transferred in another tube. Second, the residue was reconstituted with $200 \mu \mathrm{L}$ methanol-water $(80: 20, \mathrm{v} / \mathrm{v})$ and centrifuged at $14,000 \mathrm{rpm}$ for $10 \mathrm{~min}$. Finally, the supernatants were passed through a $0.22 \mu \mathrm{m}$ membrane filter, and $1 \mu \mathrm{L}$ sample was injected into the UHPLC/Q-TOF MS system for analysis.

2.3.2. Urine. The solid phase extraction (SPE) method was used for handling urine samples with Bond Elut C18 cartridges $(3 \mathrm{~mL}, 500 \mathrm{mg})$. Each cartridge was activated with $2 \mathrm{~mL}$ methanol and conditioned by $2 \mathrm{~mL}$ water. Then, $100 \mu \mathrm{L}$ of the spiked urine samples was loaded on to the cartridges. Then, $2 \mathrm{~mL}$ water and $2 \mathrm{~mL}$ methanol were added separately to the SPE cartridges to elute the matrix and the metabolites. The methanol elution was collected and dried. Then, the residue was redissolved with $200 \mu \mathrm{L}$ methanol-water $(80: 20$, $\mathrm{v} / \mathrm{v}$ ) and centrifuged at $14,000 \mathrm{rpm}$ for $10 \mathrm{~min}$. After the supernatants were passed through a $0.22 \mu \mathrm{m}$ membrane filter, $1 \mu \mathrm{L}$ samples of the filtrates was injected into the UHPLC/Q-TOF MS system for analysis.

2.3.3. Bile. Bile samples were also prepared with the SPE method, and the procedure was similar to urine sample, except that $100 \mu \mathrm{L}$ bile residue was redissolved with $150 \mu \mathrm{L}$ methanol-water $(80: 20, \mathrm{v} / \mathrm{v})$.

2.3.4. Feces. First, the spiked drying feces were grinded into fines. Weighted $1 \mathrm{~g}$ feces sample into a $50 \mathrm{~mL}$ tube and added $20 \mathrm{~mL}$ methanol-water $(80: 20, \mathrm{v} / \mathrm{v})$. Second, $15 \mathrm{~min}$ 
ultrasonic extraction was used for feces sample preparation and then centrifuged at 3,500 rpm for $10 \mathrm{~min}$ to participate impurity. A curtain amount of the supernatants were continually centrifuged at $14,000 \mathrm{rpm}$ for $10 \mathrm{~min}$ and passed through a $0.22 \mu \mathrm{m}$ membrane filter and used for mass analysis.

2.4. UHPLC and MS Conditions. The chromatography separation was carried out using a Waters ACQUITY BEH C18 column $(2.1 \times 100 \mathrm{~mm}, 1.7 \mu \mathrm{m}$, Waters, Milford, MA, USA) at the column temperature of $40^{\circ} \mathrm{C}$. The mobile phase consisted of (A) water containing $0.1 \%$ formic acid and (B) acetonitrile containing $0.1 \%$ formic acid with a gradient elution as follows: $0-1 \mathrm{~min}, 5 \% \mathrm{~A} ; 1-10 \mathrm{~min}, 5 \%-95 \% \mathrm{~A}$; and $10-12 \mathrm{~min}, 95 \% \mathrm{~A}$. The flow rate was maintained at $0.4 \mathrm{~mL} /$ min, and $1.0 \mu \mathrm{L}$ of the control and MC-containing biological samples were injected into the system at each run.

Metabolite identification of MC in rat was performed on Waters quadrupole time-of-flight (Q-TOF) Xevo G2 (Waters, Manchester, UK) equipped with an electrospray ionization (ESI) source. The capillary voltage of the ESI source was set at $3.0 \mathrm{kV}$ in the positive ionization mode. The cone voltage was set at $40 \mathrm{eV}$. Source and desolvation temperatures were set at $120^{\circ} \mathrm{C}$ and $450^{\circ} \mathrm{C}$, respectively. The nebulization gas flow was set at $800 \mathrm{~L} / \mathrm{h}$. All data were acquired with the $\mathrm{MS}^{\mathrm{E}}$ method in the resolution mode with $6 \mathrm{eV}$ as low-collision energy and 20-60 eV ramp as high-collision energy. Both the molecular ions and the mass fragment ions could be acquired in a single run. Mass data were collected over the range of m/z 100-1500 in both functions. Leucineenkephalin (m/z 556.2771) was used as real-time lock mass.

\section{Results and Discussion}

3.1. Mass Spectrometric Analysis of MC. The structures of meridianins A-G are shown in Figure 1. There are five main fragment ions of $\mathrm{MC}$ in the high-resolution spectrum (Figure 2). The speculated formula, observed and calculated mass, and mass errors are given in Table 1 . The detected mass errors ranged from 0 to $-5.3 \mathrm{mDa}$, indicating a good accuracy. The fragment ion structures are shown in Figure 2. Some fragments displayed a few ion clusters, and only one ion is given.

3.2. Metabolites Identification of MC [17]. A novel strategy was proposed for the systematic screening and characterization of MC metabolites. First, the MSE data of both the blank control samples and the biological samples containing MC were acquired using UHPLC-Q/TOF MS. Second, with the help of MetaboLynx ${ }^{\mathrm{TM}}$ software, the molecular weights, the elemental compositions, and the proposed metabolic pathways of the metabolites derived from the accurate mass measurements can be automatically predicted. Finally, the structures of metabolites were justified based on the mass difference, the characteristic fragments of MC metabolites, and available literatures data.

The presence of the isotope pattern resulting from bromine atoms means that it is not lost via the metabolism.
Both $\mathrm{Br}^{79}$ and $\mathrm{Br}^{81}$ isotopes were monitored by the mass spectrometer. The corresponding high-resolution mass spectrum displays identical isotopic cluster in an $1: 1$ ratio with two Da difference, thus confirming the presence of one bromine atom in the structure (such as $\mathrm{m} / \mathrm{z} 289.01 / 291.01$ in Figure 2). At the same time, the high-resolution mass spectrum without the isotopic cluster in $1: 1$ ratio indicates that the molecular has lost the bromine atom in the fragmentation process (such as $\mathrm{m} / \mathrm{z} 209.08,193.07,169.08$, and 140.05 in Figure 2).

The extracted ion chromatograms (EICs) of the prototypes and metabolites in MC-containing rat biological samples are shown in Figure 3, which were generated with MetaboLynx software and also be confirmed by manually extracting in the matrix (Supplementary Figure S2). The parameters of the 14 metabolites (including the prototype) are given in Table 2.

3.2.1. Identification of Parent Drug in Rat Biological Samples (M10). The metabolite M10 displayed the same molecular ion at 289.01/291.01 $\left(\mathrm{C}_{12} \mathrm{H}_{9} \mathrm{BrN}_{4}\right.$, retention time $\left.4.21 \mathrm{~min}\right)$, and the fragment ions were similar to those of MC. M10 was identified as the parent drug MC by comparing the retention time and accurate mass spectra with that of the authentic standard.

3.2.2. Hydroxylated Metabolites (M3, M6, and M12). M3, M6, and M12 displayed the same molecular ion at m/z $305.00 \quad\left(\mathrm{C}_{12} \mathrm{H}_{9} \mathrm{BrN}_{4} \mathrm{O}\right.$, retention times $3.24,3.61$ and $4.47 \mathrm{~min})$, which was $16 \mathrm{Da}(\mathrm{O})$ higher than the protonated molecule of MC. The characteristic fragment ions at $\mathrm{m} / \mathrm{z}$ 289/291 indicate the loss of $\mathrm{O}$ atom. Therefore, M3, M6, and M12 were identified as hydroxylated metabolites of MC. By retrieving literature [18], the most probable conjugate cite was at the N position. The diagnostic ion of M3 and M6 at m/ z 185 was 16 Da higher than the characteristic ion at m/z 169 of MC (Figure 2). Thus, it was proposed that the $\mathrm{O}$ atom conjugated at the A or B rings. 1-N-site in $\mathrm{B}$ ring was the most proposed conjugated site [19], and thereby, M3 with a relative higher amount should be $1-\mathrm{N}$-hydroxylate MC. M12, without the ion of $\mathrm{m} / \mathrm{z} 185$, was speculated to be $2^{\prime}-\mathrm{N}-$ hydroxylate MC.

3.2.3. Hydroxylated and Sulfate Metabolites (M2 and M11). $\mathrm{M} 2$ and M11 with protonated molecular isotopic ions at m/z $384.96\left(\mathrm{C}_{12} \mathrm{H}_{9} \mathrm{BrN}_{4} \mathrm{O}_{4} \mathrm{~S}\right.$, retention time 2.97 and $\left.4.37 \mathrm{~min}\right)$ were $80 \mathrm{Da}\left(\mathrm{SO}_{3}\right)$ higher than the protonated molecule of M3. The characteristic fragment ions at $\mathrm{m} / \mathrm{z} \quad 331$ $\left(\mathrm{M}+\mathrm{H}-\mathrm{SO}_{3}\right)$ indicated that they were hydroxylated and sulfate metabolites of MC. As illustrated in Figure 4, the major fragment ions at $\mathrm{m} / \mathrm{z} 305\left[\mathrm{M}+\mathrm{H}-\mathrm{SO}_{3}\right]^{+}, \mathrm{m} / \mathrm{z} 289$ $\left[\mathrm{M}+\mathrm{H}-\mathrm{SO}_{3}-\mathrm{O}\right]^{+}, \mathrm{m} / \mathrm{z} 226\left[\mathrm{M}+\mathrm{H}-\mathrm{SO}_{3}-\mathrm{Br}\right]^{+}$, and $\mathrm{m} / \mathrm{z} 185$ $\left[\mathrm{M}+\mathrm{H}-\mathrm{SO}_{3}-\mathrm{Br}-\mathrm{N}_{2} \mathrm{CH}_{3}\right]^{+}$were found in the high-resolution spectrum. Both M2 and M11 contain the same fragment isotopic ion clusters of $\mathrm{m} / \mathrm{z} 305 / 307,289 / 291$, and mono ion of $\mathrm{m} / \mathrm{z} 209$ in the high-resolution spectrum, which indicates the continuous loss of $\mathrm{SO}_{3}, \mathrm{O}$, and $\mathrm{Br}$ by the accurate mass 


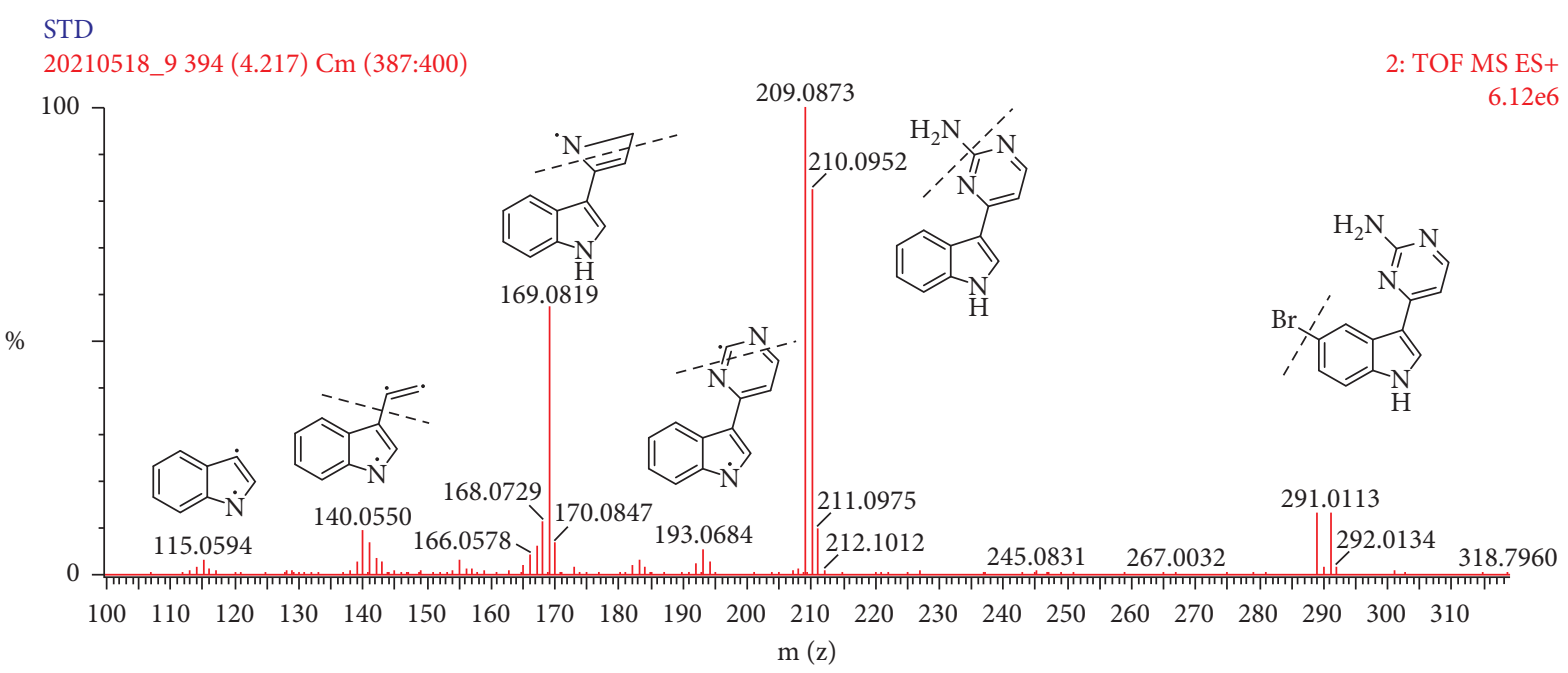

FIGURE 2: The product ion spectra and proposed fragmentation pathways of meridianin C.

TABLE 1: Empirical formula, observed and calculated mass, and mass errors of the principal fragment ions observed in the product ion mass spectrum of $[\mathrm{MC}+\mathrm{H}]^{+}$.

\begin{tabular}{lcccc}
\hline No. & Predicted formula & Calculated mass $(\mathrm{Da})$ & Observed mass $(\mathrm{Da})$ & Error $(\mathrm{mDa})$ \\
\hline 1 & $\mathrm{C}_{12} \mathrm{H}_{9} \mathrm{~N}_{4} \mathrm{Br}^{+}$ & 289.0089 & 289.0131 & -4.2 \\
2 & $\mathrm{C}_{12} \mathrm{H}_{10} \mathrm{~N}_{4}^{+}$ & 210.0905 & 210.0952 & -4.7 \\
3 & $\mathrm{C}_{12} \mathrm{H}_{7} \mathrm{~N}_{3}^{+}$ & 193.0640 & 193.0684 & -4.4 \\
4 & $\mathrm{C}_{12} \mathrm{H}_{9} \mathrm{~N}_{2}^{+}$ & 169.0766 & 169.0819 & -5.3 \\
5 & $\mathrm{C}_{10} \mathrm{H}_{9} \mathrm{~N}^{+}$ & 140.0500 & 140.0550 & -5.0 \\
\hline
\end{tabular}

${ }^{a}$ The predicted formula was regardless of the ions.

measurement. The diagnostic ion of $\mathrm{M} 2$ at $\mathrm{m} / \mathrm{z} 185$ was $16 \mathrm{Da}$ higher than the characteristic ion at $\mathrm{m} / \mathrm{z} 169$ of $\mathrm{MC}$ (Figure 2), and thereby, the $\mathrm{O}$ atom conjugating at the $\mathrm{A}$ or $\mathrm{B}$ rings was put forward. $1-\mathrm{N}$-site in $\mathrm{B}$ ring was the most proposed conjugated site $[18,19]$. While the absence of $\mathrm{m} / \mathrm{z}$ 185 suggested that the $\mathrm{O}$ atom might conjugate at $\mathrm{C}$ ring, the most proposed conjugated site might be at $2^{\prime}-\mathrm{N}$ - in $\mathrm{C}$ ring. The subsequent fragmentation ions at $\mathrm{m} / \mathrm{z} 170,143$, and so on are similar to those of $\mathrm{MC}$, which was undergoing an easy loss of $\mathrm{O}$ atom followed by subsequent fragmentation. The characteristic fragment ion of M11 at m/z 198 generated a relatively high response, which was the absence of $\mathrm{M} 2$. It is tentatively deduced that the fragment m/z 198 was generated based on a rearrangement owing to fragmentation, when $\mathrm{O}$ atom conjugated at $2^{\prime}-\mathrm{N}$ position, as shown in Figure 1. Meanwhile, the $2^{\prime}$-N-O-S bond in $\mathrm{C}$ ring speculated easier break-up, encountering a high collision energy than 1-N-O$\mathrm{S}$ bond in $\mathrm{B}$ ring because the extraction ion chromatograph of protonated molecular ion of M11 was hard to see. The calculated 1-octanol/water partition coefficient (CLog P) value was an important parameter for the metabolite identification, as an ingredient with a higher CLog $P$ value may be eluted later when separated in the reversed-phase column. The CLog $P$ values were calculated with ChemBioDraw Ver.14.0. The calculated CLog $P$ values of 1-N and $2^{\prime}$-N-hydroxylated MC were 2.0 and 2.9, respectively. Thus, the hydroxylated and sulfate or glucuronide metabolites may present an early elution conjugating at 1-N-O- and a later elution at $2^{\prime}-\mathrm{N}-\mathrm{O}$-site. The high-resolution spectrum and the mass fragment of M2 and M11 are shown in Figure 4. M2 and M11 were tentatively identified as MC-1-N-O-sulfation and $\mathrm{MC}-2^{\prime}-\mathrm{N}-\mathrm{O}$-sulfation, respectively.

3.2.4. Hydroxylated and Glucuronide Metabolites (M1 and M9). M1 and M9 with protonated molecular ion at $\mathrm{m} / \mathrm{z}$ $481.04\left(\mathrm{C}_{18} \mathrm{H}_{17} \mathrm{BrN}_{4} \mathrm{O}_{7}, \mathrm{RT}=2.49\right.$ and $\left.3.85 \mathrm{~min}\right)$ were $176 \mathrm{Da}\left(\mathrm{C}_{6} \mathrm{H}_{8} \mathrm{O}_{6}\right)$ higher than the protonated molecular ion of hydroxylated MC. Glucuronide conjugates have their characteristic mass fragment in metabolite identification because the high collision energy spectrum of glucuronide conjugates always shows the loss of $176 \mathrm{Da}\left(\mathrm{C}_{6} \mathrm{H}_{8} \mathrm{O}_{6}\right)$. As illustrated in Figure 5, the major fragment ions at $\mathrm{m} / \mathrm{z} 305$ $[\mathrm{M}+\mathrm{H}-\mathrm{GluA}]^{+}, \mathrm{m} / \mathrm{z} 289[\mathrm{M}+\mathrm{H}-\mathrm{GluA}-\mathrm{O}]^{+}$, and $\mathrm{m} / \mathrm{z} 226$ $[\mathrm{M}+\mathrm{H}-\mathrm{GluA}-\mathrm{O}-\mathrm{Br}]^{+}$were found in the positive ion mode. M1 demonstrated the diagnostic ion at $\mathrm{m} / \mathrm{z} 185$, which was absent in M9. Repeating the same approach of hydroxylated and sulfate metabolite identification (Section 3.2.3), M1 and M9 were deduced to be MC-1-N-O-glucuronidation and MC-2'-N-O-glucuronidation, respectively. The proposed fragmentation pathways of M1 and M9 are shown in Figure 5.

3.2.5. Glucuronide Metabolites (M4, M5, and M7). These metabolites had the same protonated molecular ion at $\mathrm{m} / \mathrm{z}$ $465.04\left(\mathrm{C}_{18} \mathrm{H}_{17} \mathrm{BrN}_{4} \mathrm{O}_{6}\right.$, retention times 3.33, 3.38, and $3.75 \mathrm{~min})$, which was $176 \mathrm{Da}\left(\mathrm{C}_{6} \mathrm{H}_{8} \mathrm{O}_{6}\right)$ higher than the protonated molecular ion of MC. Diagnostic losses of 

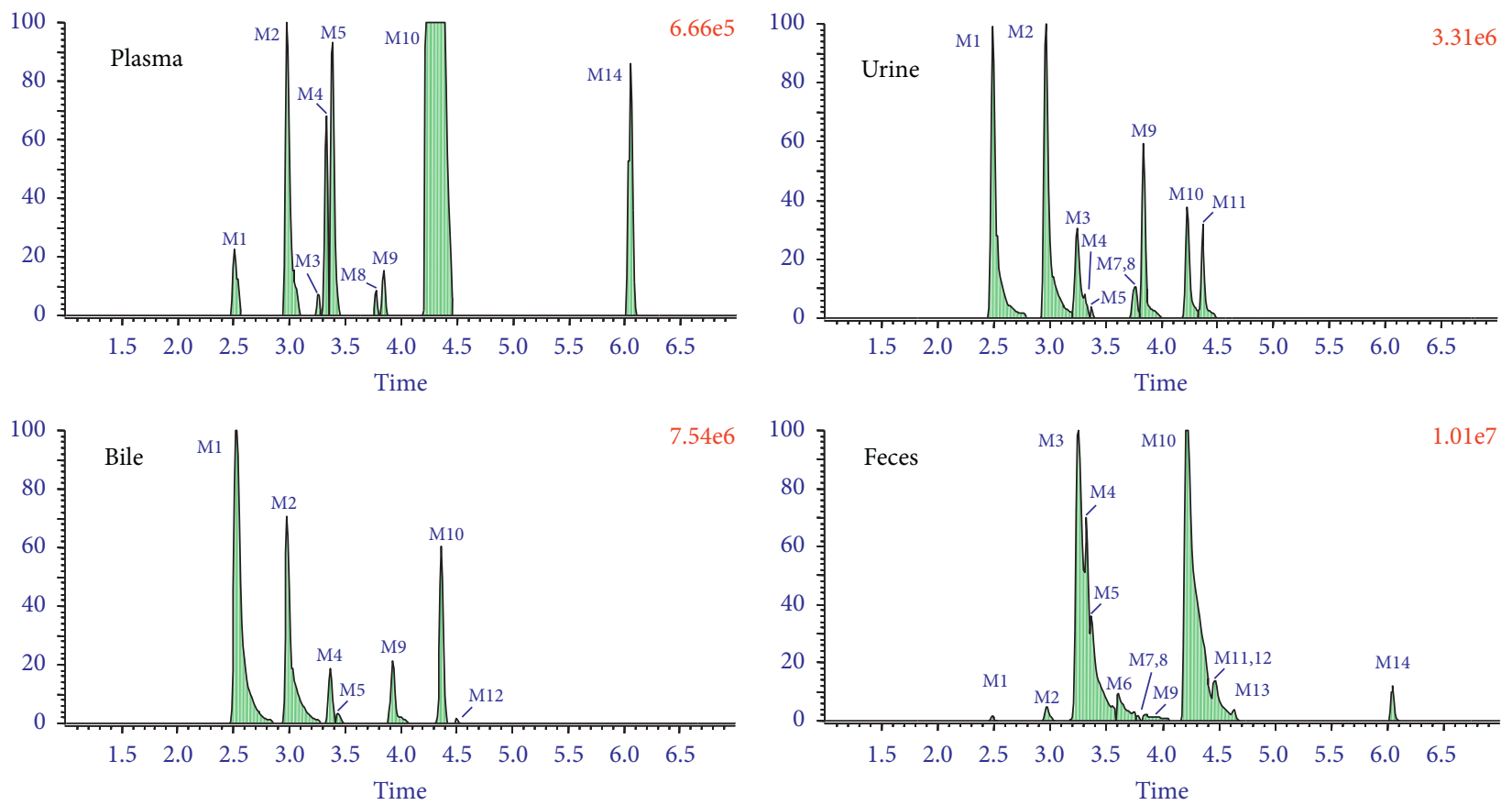

FIGURE 3: Extracted ion chromatograms (EICs) of the metabolites in meridianin C-containing rat biological samples identified by UHPLC/ Q-TOF MS in the positive ion mode.

TABLE 2: UHPLC/Q-TOF MS analysis MC and its metabolites in rat plasma, bile, urine, and feces.

\begin{tabular}{|c|c|c|c|c|c|c|c|}
\hline $\begin{array}{l}\mathrm{RT} \\
(\mathrm{min})\end{array}$ & No. & $\begin{array}{l}\text { Calculated } \\
\text { mass }\end{array}$ & $\begin{array}{l}\text { Observed mass }(\mathrm{Da}) \\
\text { fragment ions }{ }^{\mathrm{a}}\end{array}$ & $\begin{array}{c}\text { Error } \\
(\mathrm{mDa})^{\mathrm{b}}\end{array}$ & Metabolite name & Formula & Matrix $^{c}$ \\
\hline 2.49 & M1 & 481.0359 & $\begin{array}{c}481.0365 / 483.03,305.00 / \\
307.00,226.09,185.07\end{array}$ & -0.6 & Hydroxylation + glucuronide & $\mathrm{C}_{18} \mathrm{H}_{17} \mathrm{BrN}_{4} \mathrm{O}_{7}$ & $\begin{array}{c}\mathrm{P}, \mathrm{B}, \mathrm{U}, \\
\mathrm{F}\end{array}$ \\
\hline 2.97 & M2 & 384.9606 & $\begin{array}{c}384.9613 / 386.96,305.00 / \\
307.00,226.09,209.06 \\
197.08,185.07\end{array}$ & -0.7 & Hydroxylation + sulfation & $\mathrm{C}_{12} \mathrm{H}_{9} \mathrm{BrN}_{4} \mathrm{O}_{4} \mathrm{~S}$ & $\begin{array}{l}\mathrm{P}, \mathrm{B}, \mathrm{U}, \\
\mathrm{F}\end{array}$ \\
\hline 3.24 & M3 & 305.0038 & $\begin{array}{c}305.0118 / 307.01,289.01, \\
226.09,185.07\end{array}$ & -8.0 & Hydroxylation & $\mathrm{C}_{12} \mathrm{H}_{9} \mathrm{BrN}_{4} \mathrm{O}$ & $\mathrm{P}, \mathrm{U}, \mathrm{F}$ \\
\hline 3.33 & M4 & 465.0410 & $465.0421 / 467.0406$ & -1.1 & Glucuronide conjugation & $\mathrm{C}_{18} \mathrm{H}_{17} \mathrm{BrN}_{4} \mathrm{O}_{6}$ & $\mathrm{P}, \mathrm{U}, \mathrm{F}$ \\
\hline 3.38 & M5 & 465.0410 & $\begin{array}{c}465.0416,305.00 / 307.00 \\
226.08,210.09,185.07 \\
169.08\end{array}$ & -0.6 & Glucuronide conjugation & $\mathrm{C}_{18} \mathrm{H}_{17} \mathrm{BrN}_{4} \mathrm{O}_{6}$ & $\begin{array}{l}\mathrm{P}, \mathrm{B}, \mathrm{U}, \\
\mathrm{F}\end{array}$ \\
\hline 3.61 & M6 & 305.0038 & $\begin{array}{c}305.0043 / 307.00,289.01 / \\
291.01\end{array}$ & -0.5 & Hydroxylation & $\mathrm{C}_{12} \mathrm{H}_{9} \mathrm{BrN}_{4} \mathrm{O}$ & $\mathrm{F}$ \\
\hline 3.75 & M7 & 465.0410 & $\begin{array}{c}465.0408,289.01 / 291.01 \\
210.09,169.08\end{array}$ & 0.2 & Glucuronide conjugation & $\mathrm{C}_{18} \mathrm{H}_{17} \mathrm{BrN}_{4} \mathrm{O}_{6}$ & $\mathrm{U}, \mathrm{F}$ \\
\hline 3.78 & M8 & 320.9987 & $\begin{array}{c}320.9985 / 322.9968 \\
481.0359 / 483.03,305.00 /\end{array}$ & 0.2 & 2x Hydroxylation & $\mathrm{C}_{12} \mathrm{H}_{9} \mathrm{BrN}_{4} \mathrm{O}_{2}$ & $\mathrm{P}, \mathrm{U}, \mathrm{F}$ \\
\hline 3.85 & M9 & 481.0359 & $\begin{array}{l}307.00,226.09,209.06 \\
198.09,143.06\end{array}$ & 0.0 & Hydroxylation + glucuronide & $\mathrm{C}_{18} \mathrm{H}_{17} \mathrm{BrN}_{4} \mathrm{O}_{7}$ & $\begin{array}{l}\mathrm{P}, \mathrm{B}, \mathrm{U}, \\
\mathrm{F}\end{array}$ \\
\hline 4.22 & M10 & 289.0089 & $\begin{array}{c}289.0089 / 291.01,209.08 \\
169.08,140.05\end{array}$ & 0.0 & Parent & $\mathrm{C}_{12} \mathrm{H}_{9} \mathrm{BrN}_{4}$ & $\begin{array}{l}\mathrm{P}, \mathrm{B}, \mathrm{U}, \\
\mathrm{F}\end{array}$ \\
\hline 4.37 & M11 & 384.9606 & $\begin{array}{c}384.9608 / 386.96,305.00 / \\
307.00,226.09,209.06 \\
198.09,185.07,143.06\end{array}$ & -0.2 & Hydroxylation + sulfation & $\mathrm{C}_{12} \mathrm{H}_{9} \mathrm{BrN}_{4} \mathrm{O}_{4} \mathrm{~S}$ & $\begin{array}{c}\mathrm{P}, \mathrm{B}, \mathrm{U}, \\
\mathrm{F}\end{array}$ \\
\hline 4.47 & M12 & 305.0038 & $\begin{array}{c}305.0041 / 307.00,289.01 / \\
291.01,169.08\end{array}$ & -0.3 & Hydroxylation & $\mathrm{C}_{12} \mathrm{H}_{9} \mathrm{BrN}_{4} \mathrm{O}$ & $\mathrm{B}, \mathrm{F}$ \\
\hline 4.63 & M13 & 336.9936 & $\begin{array}{c}334.9955 / 336.9951,318.97 \\
320.97\end{array}$ & -1.9 & $3 x$ hydroxylation & $\mathrm{C}_{12} \mathrm{H}_{9} \mathrm{BrN}_{4} \mathrm{O}_{3}$ & $\mathrm{~F}$ \\
\hline 6.06 & M14 & 445.0148 & $\begin{array}{c}443.0180 / 445.0161,288.00 / \\
290.00,246.99 / 248.99 \\
208.07,168.07\end{array}$ & -1.3 & $\begin{array}{l}\text { Hydration + glucuronide conjugation }+ \\
\qquad 2 \times \text { alcohols dehydration }\end{array}$ & $\mathrm{C}_{18} \mathrm{H}_{13} \mathrm{BrN}_{4} \mathrm{O}_{5}$ & $\mathrm{P}, \mathrm{F}$ \\
\hline
\end{tabular}

${ }^{a}$ Only characteristic fragment ions were shown. ${ }^{b}$ The mass error of molecular ions. ${ }^{c} \mathrm{U}$, urine samples; B, bile samples; P, plasma samples; F, fecal samples. 


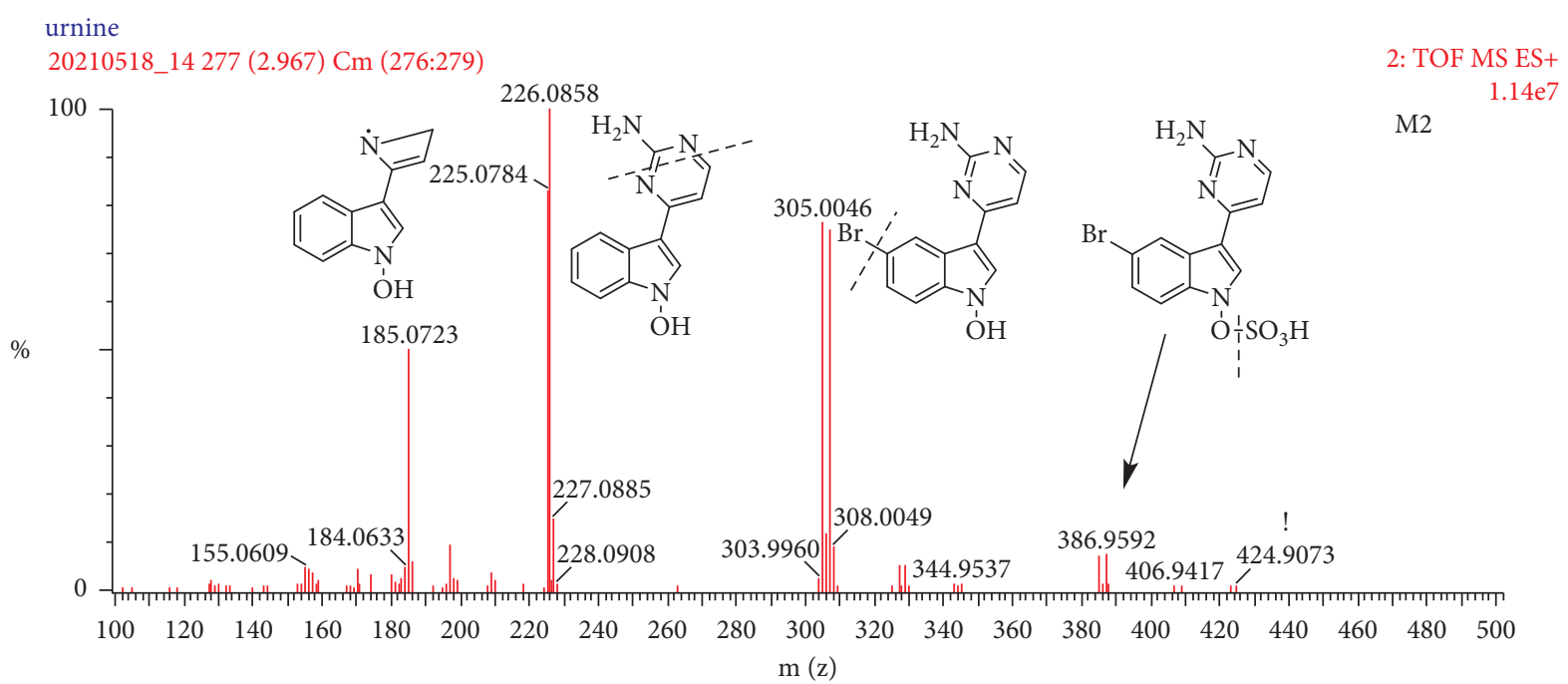

(a)

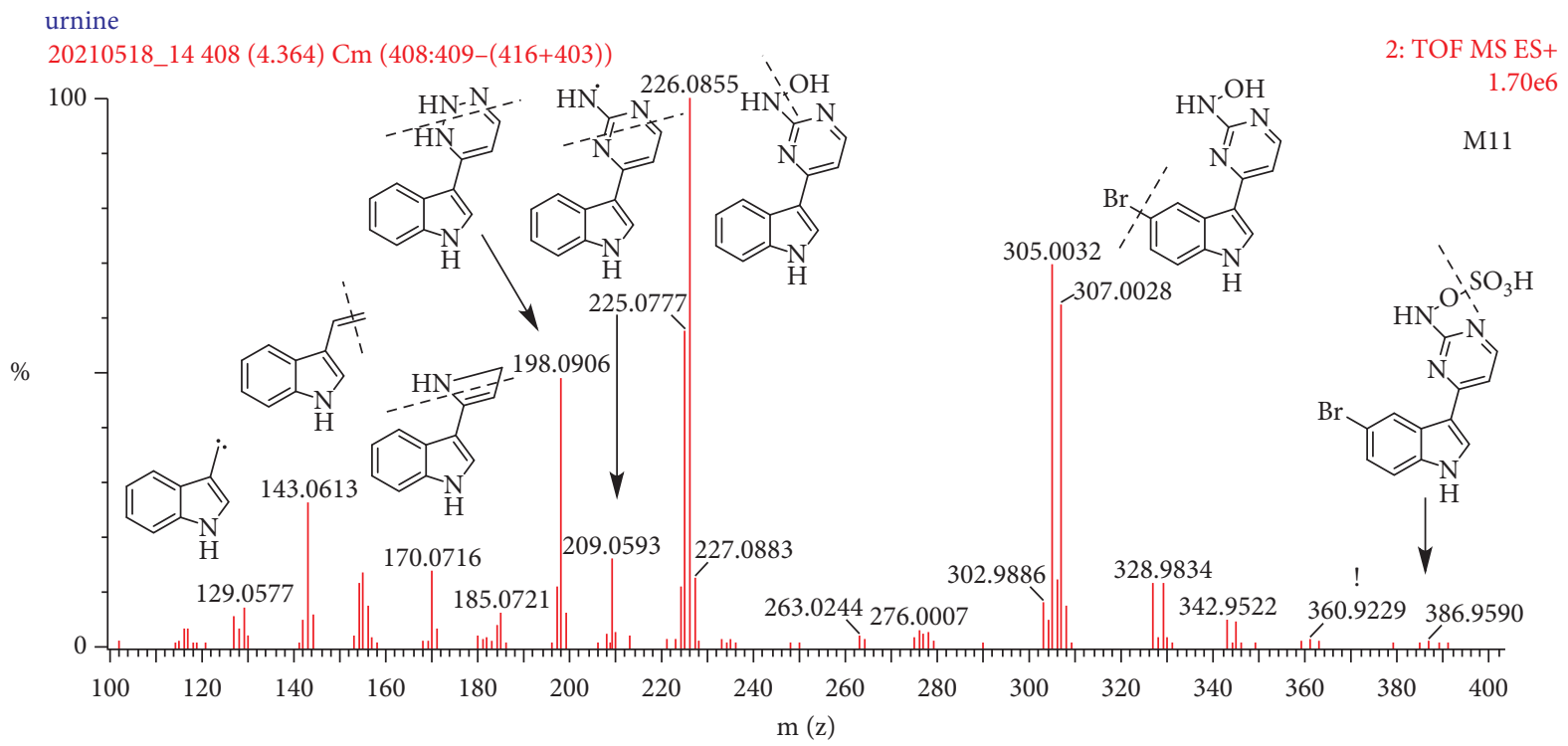

(b)

FIGURE 4: The product ion spectra and proposed fragmentation pathways of M2 and M11 in the positive ion mode.

$176 \mathrm{Da}$ were indicating a glucuronide conjugate. In the high-resolution channel, they displayed the same fragment ion at $\mathrm{m} / \mathrm{z} 289 / 291$, and so, they were speculated to be glucuronide metabolites of MC. Among them, 1-N-O- and $2^{\prime}-\mathrm{N}-\mathrm{O}-$ were the two possible conjugated sites [20-22]. We tentatively deduced M4 and M7 to be MC-1-N-glucuronidation and $\mathrm{MC}-2^{\prime}-\mathrm{N}$-glucuronidation by their elution order.

3.2.6. Dihydroxylated Metabolite (M8) and Trihydroxylated Metabolite (M13). M8 demonstrates the protonated molecular ion at $\mathrm{m} / \mathrm{z} 320.99\left(\mathrm{C}_{12} \mathrm{H}_{9} \mathrm{BrN}_{4} \mathrm{O}_{2}\right.$, retention time $3.78 \mathrm{~min}$ ), which was $32 \mathrm{Da}$ higher than the protonated molecule of MC. The major fragment ions of M8 at m/z 305 $[\mathrm{M}+\mathrm{H}-\mathrm{O}]^{+}, \quad \mathrm{m} / \mathrm{z} \quad 289 \quad[\mathrm{M}+\mathrm{H}-2 \mathrm{O}]^{+}, \quad \mathrm{m} / \mathrm{z} \quad 226$ $[\mathrm{M}+\mathrm{H}-\mathrm{O}-\mathrm{Br}]^{+}, \mathrm{m} / \mathrm{z} 209[\mathrm{M}+\mathrm{H}-2 \mathrm{O}-\mathrm{Br}]+$, and $\mathrm{m} / \mathrm{z} 169$ were found with high collision energy. M8 was identified as dihydroxylated metabolites of MC. M8 with two $\mathrm{O}$ atom conjugated at $1-\mathrm{N}$ - and $2^{\prime}-\mathrm{N}$-site, and $1,2^{\prime}-\mathrm{N}-\mathrm{OH}-\mathrm{MC}$ was the probable structure. Following similar strategy, M13 (m/z 336.99, $\mathrm{C}_{12} \mathrm{H}_{9} \mathrm{BrN}_{4} \mathrm{O}_{3}$, retention time $4.63 \mathrm{~min}$ ) displayed the characteristic fragment ions at $\mathrm{m} / \mathrm{z} 305[\mathrm{M}+\mathrm{H}-2 \mathrm{O}]^{+}, \mathrm{m} /$ $\mathrm{z} 289[\mathrm{M}+\mathrm{H}-3 \mathrm{O}]^{+}$, and $\mathrm{m} / \mathrm{z} 226[\mathrm{M}+\mathrm{H}-\mathrm{Br}-3 \mathrm{O}]^{+}$, and so, M13 was identified as the trihydroxylated metabolite of MC.

3.2.7. Other Metabolite (M14). M14 (m/z 445.016, $\mathrm{C}_{18} \mathrm{H}_{13} \mathrm{BrN}_{4} \mathrm{O}_{5}$, retention time $6.05 \mathrm{~min}$ ) was detected both in feces and plasma. The EIC and high energy spectrum of $\mathrm{M} 14$ are shown in Figure 6 . The isotopic clusters at $\mathrm{m} / \mathrm{z}$ $443.02 / 445.02,288.00 / 290.00$, and $246.99 / 248.99$ in the ratio of $1: 1$ indicated that it was the metabolite of MC. However, MetaboLynx software gave a metabolism of 


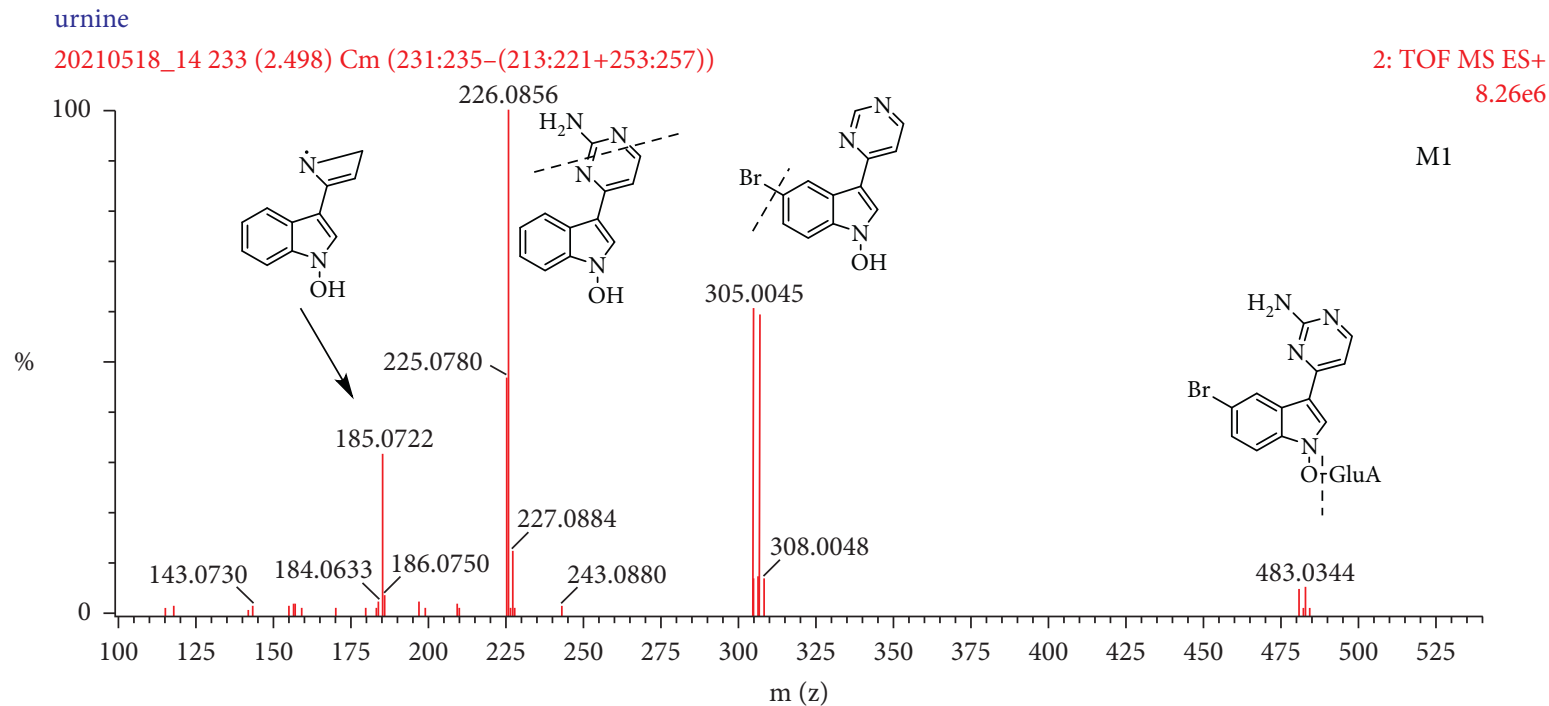

(a)

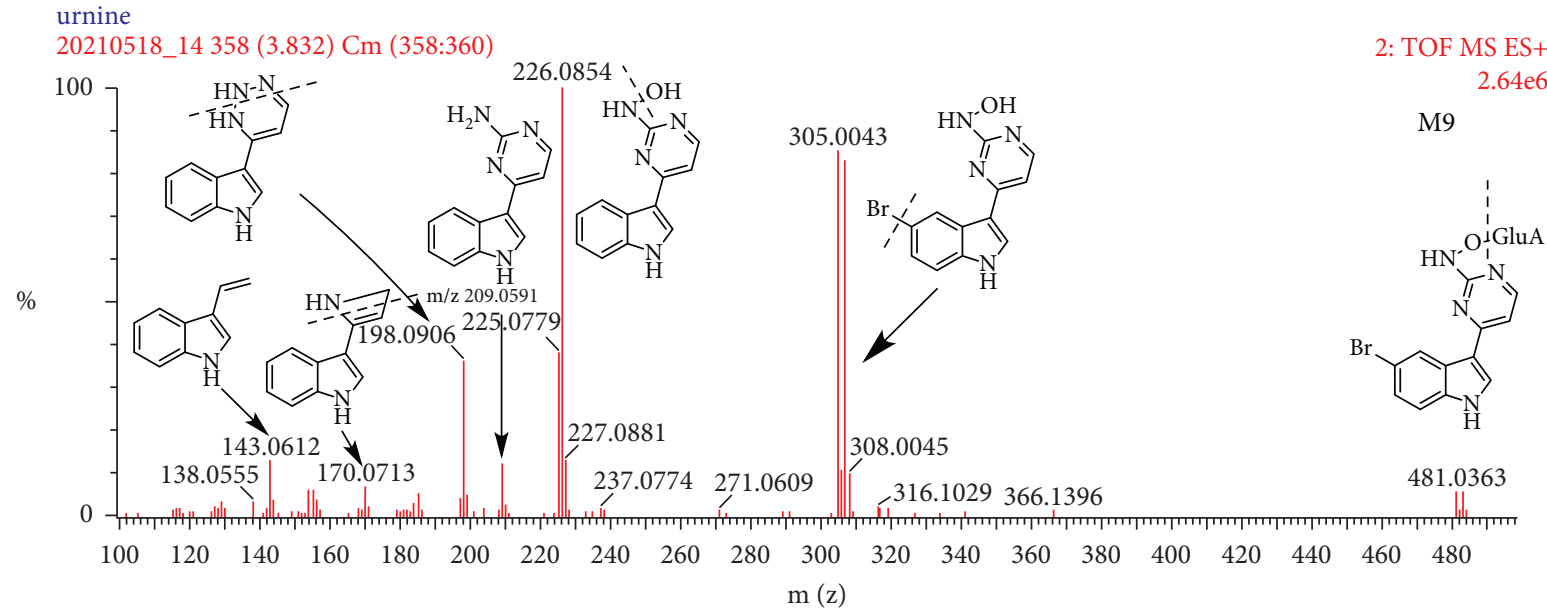

(b)

FIGURE 5: The product ion spectra and proposed fragmentation pathways of M1 and M9 in the positive ion mode.

(hydroxylation + glucuronide conjugation $)+2 \times$ alcohols dehydration, with the mass difference of $1.4 \mathrm{mDa}$. It is obvious that the skeleton of MC could not lose two $\mathrm{H}_{2} \mathrm{O}$, and so, the alcohols dehydration may happen at the conjugated glucuronide site. Given this, further study is needed to justify this presumption.

3.3. Relative Content of Metabolites. The peak area was calculated using MetaboLynx (Figure 3). The content of each metabolite was displayed as the percentage of each extraction ion chromatograph peak areas relative to the total peak areas in plasma, urine, bile, and feces sample. As the biological samples at each time were spiked together in a certain period of time, the relative content could give some useful message for the ADME study of MC in the future. As given in Table 3, about $75.8 \%$ of MC was displayed as prototype in plasma, and $11.7 \%, 9.1 \%$, and $57.7 \%$ of MC were displayed in bile, urine, and feces, respectively. About 51.5\% hydroxylated and glucuronide metabolites, as well as $20.9 \%$ hydroxylated and sulfate metabolite, existed in bile. The relative amount of metabolites in urine was similar to those in bile. Fecal samples contained the most kinds of metabolites, and hydroxylated metabolites were the major phase I metabolites, occupying nearly $20 \%$ metabolites. $13.0 \%$ hydroxylated and sulfate metabolites were the major phase II metabolites.

3.4. Result of Analysis. The UHPLC/Q-TOF MS method, combined with MetaboLynx, was employed for rapid analysis of the metabolites of MC in vivo of rats. Acetonitrile and water containing $0.1 \%$ formic acid as the mobile phase and collision energy at $20-60 \mathrm{eV}$ displayed good mass fragments of the metabolites. MetaboLynx can rapidly excavate the metabolites by comparing the blank control sample with the samples collected after administration of MC, which will dramatically reduce the mental work extraction ion chromatograph one by one and increase the accuracy and integrity. As the prototype contains bromine, 


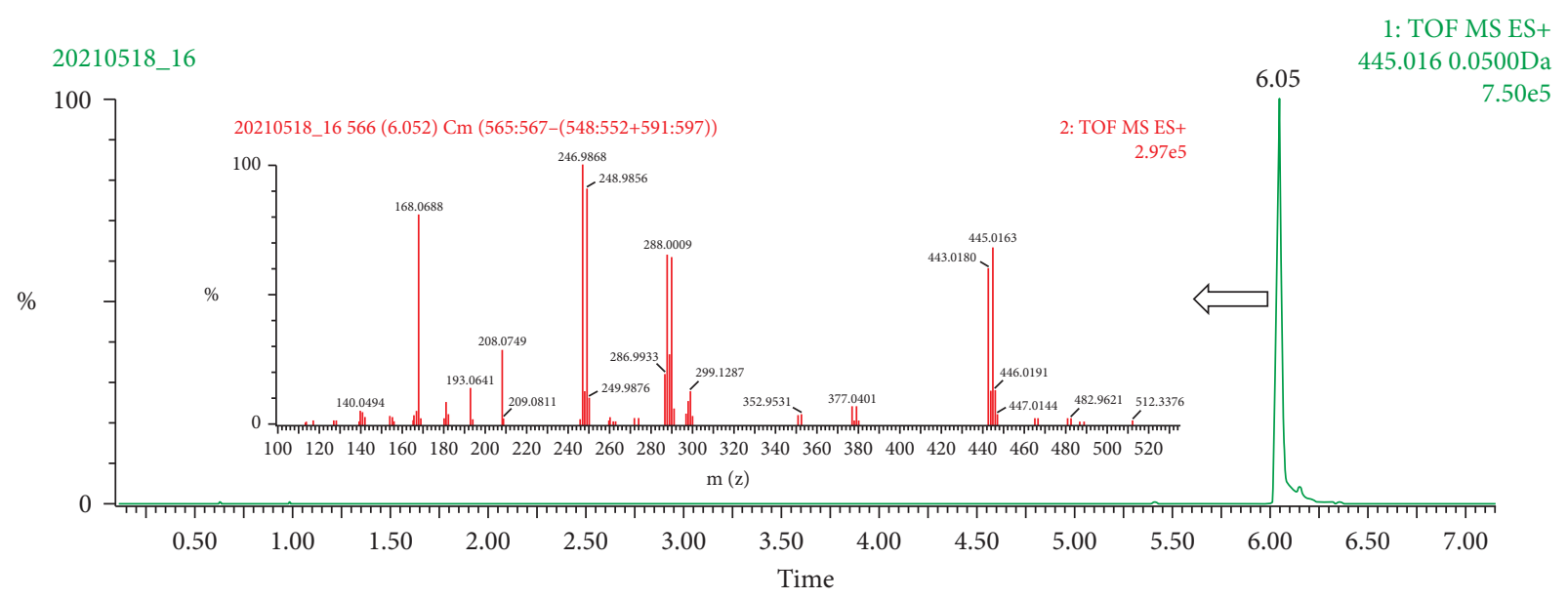

Figure 6: The EIC and high energy spectrum of M14.

TABLE 3: Relative content of 14 metabolites of MC in rat plasma, bile, urine, and feces.

\begin{tabular}{|c|c|c|c|c|c|}
\hline \multirow{2}{*}{ Metabolite } & \multirow{2}{*}{ Metabolic pathway } & \multicolumn{4}{|c|}{ Relative content (\%) } \\
\hline & & Plasma & Bile & Urine & Feces \\
\hline M1 & Hydroxylation + glucuronide conjugation & 1.4 & 45.5 & 29.2 & 0.3 \\
\hline M2 & Hydroxylation + sulfation & 6.5 & 28.2 & 29.7 & 1.0 \\
\hline M3 & Hydroxylation & 0.3 & 0.0 & 8.3 & 11.9 \\
\hline M4 & Glucuronide conjugation & 2.9 & 4.3 & 0.9 & 5.0 \\
\hline M5 & Glucuronide conjugation & 4.9 & 1.8 & 0.6 & 2.4 \\
\hline M6 & Hydroxylation & 0.0 & 0.0 & 0.0 & 4.2 \\
\hline M7 & Glucuronide conjugation & 0.0 & 0.0 & 1.5 & 0.2 \\
\hline M8 & 2x Hydroxylation & 0.3 & 0.0 & 1.3 & 0.2 \\
\hline M9 & Hydroxylation + glucuronide conjugation & 0.6 & 6.0 & 12.5 & 1.6 \\
\hline M10 & Parent & 75.8 & 11.7 & 9.1 & 57.7 \\
\hline M11 & Hydroxylation + sulfation & 3.1 & 2.7 & 6.9 & 12.0 \\
\hline M12 & Hydroxylation & 0.0 & 0.3 & 0.0 & 3.1 \\
\hline M13 & 3x Hydroxylation & 0.0 & 0.0 & 0.0 & 0.3 \\
\hline M14 & Hydration + glucuronide conjugation $+2 \times$ alcohols dehydration & 4.2 & 0.0 & 0.0 & 0.2 \\
\hline
\end{tabular}

we set the parameters of the isotopic mode, which will reduce the processing time from a few hours to a few minutes. This strategy can also be applied to evaluate the other compound metabolisms containing bromine or chlorine.

A total of 14 metabolites including the parent compound MC were found in vivo of rat. The proposed metabolic pathways of MC in rat are shown in Figure 7. The $\mathrm{N}$ - or O-glucuronidation, O-sulfation, N-hydroxylation, and dihydroxylation were the main metabolic pathways of MC. The extraction ion chromatograph of metabolites was found in samples, which was absent in blank controls. The highresolution chromatograph exists in isotopic clusters at the ratio of $1: 1$, confirming the peaks are the metabolites of MC. $\mathrm{MC}$-glucuronidation and $\mathrm{MC}-\mathrm{O}$-glucuronidation were the main metabolisms of $\mathrm{MC}$ in vivo comparing with $\mathrm{MC}$ sulfation and MC-O-sulfation. The prototype of MC displayed a high concentration in plasma, bile, urine, and feces, proposing a higher bioavailability of MC after oral administration (Table 3). At the same time, natural products in vivo mainly undergo the phase II metabolism including glucuronide and sulfate conjugates to increase polarity and decrease toxicity, then excreting out of the body. The glucuronide or sulfate conjugation at MC detected the minor metabolism, compared with glucuronide or sulfate metabolites after hydroxylation of MC, which could boil down to no hydroxyl groups in the parent skeleton (Figure 1). It could be inferred that $\mathrm{N}$-site was not active as $\mathrm{O}$-site encountering the conjugated metabolism [21]. Furthermore, no sulfate conjugated at $\mathrm{N}$-site metabolites was detected in all of the matrices, except a few $\mathrm{N}$-glucuronide conjugation, so we inferred that the $\mathrm{N}$-sulfate conjugation could hardly happen in vivo of rat [23]. The feces sample detected the most kinds of metabolites, and most of them also existed in other biological matrices. A relatively high amount of hydroxylated metabolites (almost 20\%) of MC in feces suggests that $\mathrm{MC}$ was first transformed by intestinal bacteria, and then, MC and these phase I metabolites were absorbed into the blood, suffering further metabolism including $\mathrm{N}$-, O-glucuronidation, and O-sulfation. Meanwhile, some phase II metabolisms including hydroxylation + sulfation (13.0\%), glucuronide conjugation (7.6\%), and hydroxylation + glucuronide conjugation (1.9\%) were also detected in feces, which was quite different from those in the bile, suggesting that MC might undergo some first-pass 

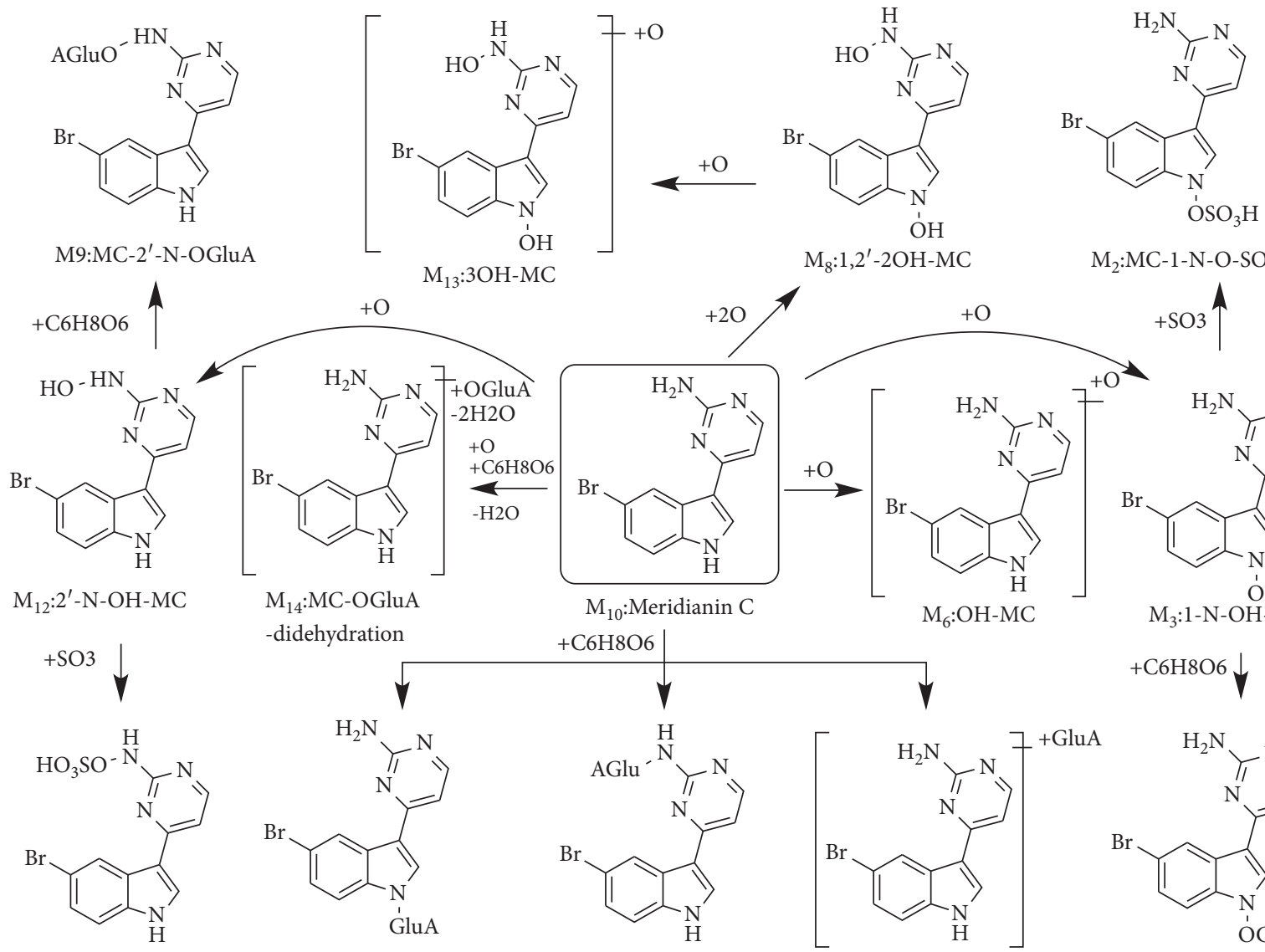

$$
\mathrm{M}_{8}: 1,2^{\prime}-2 \mathrm{OH}-\mathrm{MC}
$$

$\mathrm{M}_{2}: \mathrm{MC}-1-\mathrm{N}-\mathrm{O}-\mathrm{SO}_{3} \mathrm{H}$

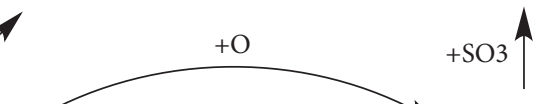

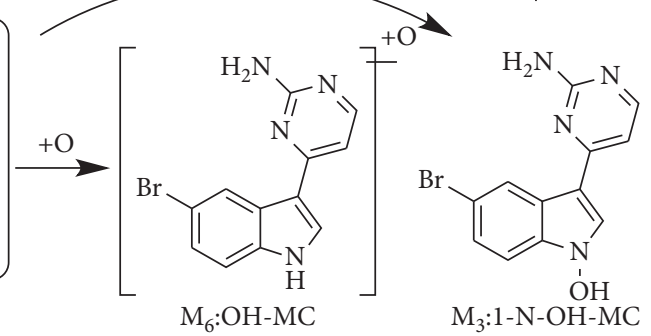

-didehydration

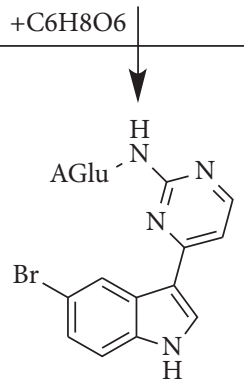

$\mathrm{M}_{7}: \mathrm{MC}-2^{\prime}-\mathrm{N}-\mathrm{GluA}$

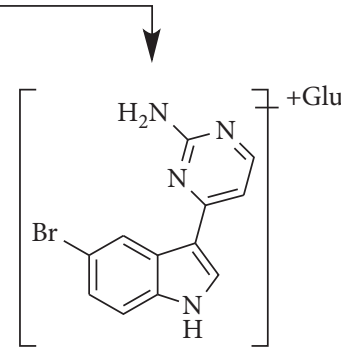

$\mathrm{M}_{5}: \mathrm{MC}-\mathrm{GluA}$

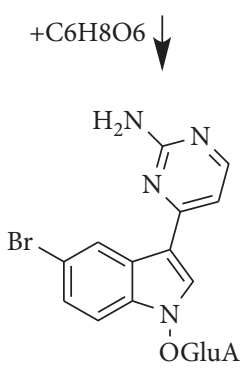

$\mathrm{M}_{1}: \mathrm{MC}-1-\mathrm{N}-\mathrm{O}-\mathrm{GluA}$

Figure 7: The proposed metabolic pathways of meridianin $\mathrm{C}$ in vivo of rat.

metabolisms in the intestine after administration. However, this is contradicted to the relatively high bioavailability of $\mathrm{MC}$ in plasma. To our surprise, the amount of metabolites in plasma was quite different from those in urine and bile. The pharmacokinetics study of MC in plasma was needed in the future. A total of almost $88 \%$ phase II metabolites of MC were detected in bile. Thus, it can be inferred that MC also undergoes some first-pass metabolisms in the liver after absorption. The relative amount of metabolites in bile is similar to those in urine and different from those in feces. We tentatively speculated that in addition to hepatoenteric circulation, MC may encounter not only the phase I but also some phase II metabolisms happening in intestine with the metabolic enzymes and bacteria in the intestine, which catalyzes the drug's metabolic response and ultimately affects drug absorption.

\section{Conclusions}

In the present study, the UHPLC/Q-TOF MS method was used to explore the metabolites of $\mathrm{MC}$ in rat, after oral administration of MC, with the help of MetaboLynx software. A total of 14 metabolites were detected in rats and were tentatively identified based on the mass spectral fragmentation patterns, elution order, or retrieving literatures. N- or
O-glucuronidation, O-sulfation, N-hydroxylation, dihydroxylation, and trihydroxylation were the major metabolisms of MC in vivo. Meanwhile, the relative content of each metabolite in each biological matrix was evaluated. Relatively high amount MC was displayed as prototype in plasma, proposing a high bioactivity of MC after oral administration. This study provides an experimental evidence for the metabolic process of $\mathrm{MC}$ and its family compounds in vivo and also provides a simple method for the rapid study of the metabolic process of bromine or chlorine containing compounds in vivo.

\section{Data Availability}

The data used to support the findings of this study are included within the manuscript and are available from the corresponding author upon request.

\section{Conflicts of Interest}

The authors declare that they have no conflicts of interest.

\section{Authors' Contributions}

Guozhe Zhang performed and designed the experiments, analyzed the data, and wrote the manuscript. Linxia Xiao 
helped with the data analysis. Liang Qi conceived and designed the experiments. All authors approved the final manuscript.

\section{Acknowledgments}

This work was financially supported by Jiangsu Provincial Higher Education Natural Science Foundation (19KJB350010) and the 2018 Jiangsu Commission of Health Foundation from Jiangsu province, China (Z2017017).

\section{Supplementary Materials}

Supplementary Figure S1. ${ }^{1} \mathrm{H}$ NMR of meridianin C. Supplementary Figure S2. EIC of 14 metabolites. (Supplementary Materials)

\section{References}

[1] J. A. DiMasi, H. G. Grabowski, and R. W. Hansen, "Innovation in the pharmaceutical industry: new estimates of R\&D costs," Journal of Health Economics, vol. 47, pp. 20-33, 2016.

[2] D. C. Evans, A. P. Watt, D. A. Nicoll-Griffith, and T. A. Baillie, "Drug-protein adducts: an industry perspective on minimizing the potential for drug bioactivation in drug discovery and development," Chemical Research in Toxicology, vol. 17, no. 1, pp. 3-16, 2004.

[3] Z. Zhang and W. Tang, "Drug metabolism in drug discovery and development," Acta Pharmaceutica Sinica B, vol. 8, no. 5, pp. 721-732, 2018.

[4] F. Cuyckens, "Mass spectrometry in drug metabolism and pharmacokinetics: current trends and future perspectives," Rapid Communications in Mass Spectrometry, vol. 33, no. Suppl 3, pp. 90-95, 2019.

[5] M. A. Radwan and M. El-Sherbiny, "Synthesis and antitumor activity of indolylpyrimidines: marine natural product meridianin D analogues," Bioorganic \& Medicinal Chemistry, vol. 15, no. 3, pp. 1206-1211, 2007.

[6] T. Rodrigues, D. Reker, P. Schneider, and G. Schneider, "Counting on natural products for drug design," Nature Chemistry, vol. 8, no. 6, pp. 531-541, 2016.

[7] L. G. Copping and S. O. Duke, "Natural products that have been used commercially as crop protection agents," Pest Management Science, vol. 63, no. 6, pp. 524-554, 2007.

[8] S. Wang, G. Dong, and C. Sheng, "Structural simplification of natural products," Chemical Reviews, vol. 119, no. 6, pp. 4180-4220, 2019.

[9] W. Wu, Y. Tang, J. Yang, E. Idehen, and S. Sang, "Avenanthramide aglycones and glucosides in oat bran: chemical profile, levels in commercial oat products, and cytotoxicity to human colon cancer cells," Journal of Agricultural and Food Chemistry, vol. 66, no. 30, pp. 8005-8014, 2018.

[10] L. H. Franco, E. B. Joffe, L. Puricelli, M. Tatian, A. M. Seldes, and J. A. Palermo, "Indole alkaloids from the tunicate Aplidium meridianum," Journal of Natural Products, vol. 61, no. 9, pp. 1130-1132, 1998.

[11] M. Gompel, M. Leost, E. B. De Kier Joffe et al., "Meridianins, a new family of protein kinase inhibitors isolated from the ascidian Aplidium meridianum," Bioorganic \& Medicinal Chemistry Letters, vol. 14, no. 7, pp. 1703-1707, 2004.

[12] M. D. Lebar, K. N. Hahn, T. Mutka et al., "CNS and antimalarial activity of synthetic meridianin and psammopemmin analogs," Bioorganic \& Medicinal Chemistry, vol. 19, no. 19, pp. 5756-5762, 2011.

[13] R. R. Yadav, S. I. Khan, S. Singh, I. A. Khan, R. A. Vishwakarma, and S. B. Bharate, "Synthesis, antimalarial and antitubercular activities of meridianin derivatives," European Journal of Medicinal Chemistry, vol. 98, pp. 160-169, 2015.

[14] L. Llorach-Pares, A. Nonell-Canals, M. Sanchez-Martinez, and C. Avila, "Computer-aided drug design applied to marine drug discovery: meridianins as Alzheimer's disease therapeutic agents," Marine Drugs, vol. 15, no. 12, 2017.

[15] H. Cho, A. K. Yadav, Y. Do et al., "Antisurvival and proapoptotic effects of meridianin C derivatives on MV411 human acute myeloid leukemia cells," International Journal of Oncology, vol. 56, no. 1, pp. 368-378, 2019.

[16] N. S. Park, Y. K. Park, M. Ramalingam et al., "Meridianin C inhibits the growth of YD-10B human tongue cancer cells through macropinocytosis and the down-regulation of Dickkopf-related protein-3," Journal of Cellular and Molecular Medicine, vol. 22, no. 12, pp. 5833-5846, 2018.

[17] G. Zhang, J. Sun, Y. Kano, and D. Yuan, "Metabolic profile of irisolidone in rats obtained by ultra-high performance liquid chromatography/quadrupole time-of-flight mass spectrometry," Journal of Pharmaceutical and Biomedical Analysis, vol. 941, pp. 1-9, 2015.

[18] S. Aprile, R. Canavesi, R. Matucci, C. Bellucci, E. Del Grosso, and G. Grosa, "New insights in the metabolism of oxybutynin: evidence of $\mathrm{N}$-oxidation of propargylamine moiety and rearrangement to enaminoketone," Xenobiotica, vol. 48 , no. 5 , pp. 478-487, 2018.

[19] H. X. Fan, Z. Q. Zhou, J. Peng et al., "A microbial model of mammalian metabolism: biotransformation of 4,5-dimethoxyl-canthin-6-one using Cunninghamella blakesleeana CGMCC 3.970," Xenobiotica, vol. 47, no. 4, pp. 284-289, 2017.

[20] S. H. Chiu and S. W. Huskey, "Species differences in N-glucuronidation," Drug Metabolism \& Disposition, vol. 26, no. 9, pp. 838-847, 1998.

[21] S. Lentini, D. van der Mey, A. Kern et al., "Absorption, distribution, metabolism and excretion of molidustat in healthy participants," Basic and Clinical Pharmacology and Toxicology, vol. 127, no. 3, pp. 221-233, 2020.

[22] S. Kaivosaari, M. Finel, and M. Koskinen, "N-glucuronidation of drugs and other xenobiotics by human and animal UDPglucuronosyltransferases," Xenobiotica, vol. 41, no. 8, pp. 652-669, 2011.

[23] K. Holmborn, J. Ledin, E. Smeds, I. Eriksson, M. KuscheGullberg, and L. Kjellen, "Heparan sulfate synthesized by mouse embryonic stem cells deficient in NDST1 and NDST2 is 6-O-sulfated but contains no N-sulfate groups," Journal of Biological Chemistry, vol. 279, no. 41, pp. 42355-42358, 2004. 